Przemysław Żywiczyński

\title{
An attempt at a proxemic description of politeness from the ethological-evolutionary persepctive*
}

\section{Introductory remarks}

"A fundamental criterion for a communicative system to be a language is that it is constituted of symbols" - the statement made by Peter Gärdenfors ([2003] 2006: 147) seems to capture the dominant tone of discussion on the evolutionary emergence of language. In the literature on the subject, the appearance of "the voluntary use of discreet symbolic vocalizations" is commonly understood as the decisive step in developing the linguistic faculty (Jackendoff 2002: 239, see also Donald 1991, Deacon 1997, Aitchison 1998, and MacNeilage 2008). There is also a growing consensus that the primary function of language, as defined above, is to reliably transmit honest semantic information to nonkin as well as kin (see e.g. Krebs \& Dawkins 1984, Maynard Smith 1982, and Scott-Philips 2008)

Naturally, such a symbolic-informational position on the nature of language does not do justice to the complexity of linguistic phenomena, as was observed long ago by Roman Jakobson. According to him, on top of the referential role, which roughly speaking describes the ability of language to transmit semantic information, linguistic communication performs: the emotive function by allowing the speaker to express her attitudes towards what she is speaking about, the conative function aimed at exerting an influence on the addressee, the phatic function of establishing, prolonging, and terminating communication, the metalinguistic function

* This research was supported by grant 3704/B/H03/2011/40 from the Polish National Science Centre.

1 As will be explained, the argument presented in this paper doesn't exclude the possibility that language originated in the gestural medium. 
focused on language itself, and the poetic function of drawing attention to the organisation of a verbal message ([1960] 1999). ${ }^{2}$ In the present context, it is beside the point to analyse the accuracy of Jakobson's proposal; however, his basic insight - that language is much more than manipulation of symbols to transfer semantic information - should be considered seriously in any attempt to explain the nature of linguistic processes and their origin.

In the EoL studies, probably the most influential hypothesis which goes the beyond the confines of the symbolic-informational view of language is Robin Dunbar's vocal-grooming scenario $(1993,1996)$, which emphasises the bonding character of linguistic communication, or to use Jakobson and Malinowski's term, its phatic character. It is interesting to note that Dunbar marries the phylogentic argument about the role verbal grooming played in the emergence of language (in his view, verbal grooming substituted manual grooming as a more effective means of bonding in the growing hominid groups) with the statement on the nature of language which regards gossip, the contemporary manifestation of verbal grooming, as the essential characteristic of linguistic communication (see e.g. Dunbar et al. 1997).

His line of reasoning betrays the perspective of an evolutionary biologist looking at linguistic phenomena. Dunbar sets out with the characterisation of primate bonding behaviour and its relation to group size; then discusses the ratio between neocortex size and group size, putting this problem in the context of the hominid evolution; later goes on to argue for the necessity of hominids developing a bonding mechanism other than manual grooming, which leads him to propose the vocal-grooming scenario of language emergence; and finally supports his hypothesis with linguistic data. The argumentation used in this paper is organised in the reverse fashion - it starts from consideration of linguistic phenomena and terminates in evolutionary concerns. Accordingly, the set of linguistic phenomena which will be discussed here comes from the area of politeness. An attempt to explain their nature will lead to the hypothesis that a significant amount of linguistic politeness is rooted in human spatial behaviour related to aggression appeasement. At the last stage, this proposal will be translated into the terms of evolutionary logic and investigated from the perspective of language emergence.

2 Jakobson, elaborating on Karl Bühler's model of language (1933), anchors the functions of language in the structure of a communicative act. Thus, the referential function is orientated towards the context in which an act takes place, the emotive function, towards the addresser, the conative, towards the addressee, the phatic function is focused on the contact between the addresser and addressee, the metalinguistic one reflexively bears on the communicative code, and the poetic function, as already explained, is message-orientated (Jakobson ([1960] 1999: 48-51). 
It should be noted that Dunbar's hypothesis can be reconciled with the standard view that language emerged for the purpose of transferring semantic information, with symbolicity constituting its essential property. For example, Peter MacNeilage accommodates the vocal grooming scenario into his frame-content theory, which views the emergence of proto-words as a sequence of four events: the use of lipsmacks instead of manual grooming, the use of phonation while lipsmacking, gradual substitution of smacking together with phonation for the actual grooming, and addition of semantic information to this vocal component (2008: 95-96). In this way, vocal grooming could have played a vital role in the appearance of language symbols and, furthermore, the grooming function may still be performed by these symbols. The arguments to be presented here are similar to MacNeilage's proposal in that they concern non-symbolic uses of language, in particular the function of appeasing aggression, without denying its thoroughly (but not uniquely) symbolic character. However, unlike vocal grooming, which played - as is argued - the foundational role in the origin of speech, vocal appeasement is assumed to have appropriated the vocal medium of the already developing linguistic faculty. In relation to the last point, it should be stressed that this study is not going to shed any light on the controversy between supporters and opponents of gesturefirst theories of language origin (e,g. Hewes 1996, Armstrong et al. 1994, Corballis 2002 versus e.g. McNeill ${ }^{3}$ et al. 2005, MacNeilage 2008) - as will become clear, for aggression-appeasing politeness to arise, communication must already have been conducted vocally, that is, either during or after the hypothesised transfer from the gestural to vocal medium occurred.

\section{Politeness: setting the ground*}

As noted by Gino Eelen, politeness is now a well-established scholarly concept, fundamental to "politeness theory," which has become a widelyused tool in intercultural communication (Eelen 2001: i). He further argues that the impetus for the development of politeness research came from linguistic pragmatics and sociolinguistics, with all major theories agreeing that politeness phenomena are related to both of these fields: politeness is a matter of language use - "which warrants its classification

This section is closely based on Żywiczyński (2010 Part II) theory.

In fact, David McNeill is a key proponent of the "gesture-together-with-speech" 
within pragmatics" - and connects "language with the social world - which warrants the socio- prefix" (Eelen 2001: 1). This being so, there is a marked difference in the emphasis which different theories put on the pragmatic and the sociolinguistic elements. Accordingly, Robin Lakoff's $(1973,1975)$ and Geoffrey Leech's (1983) theories can be classified as pragmatic approaches to politeness, while Penelope Brown and Stephen Levinson (1987), Horst Arndt and Richard Janney (1985), Bruce Fraser and William Nolen (1981), and Richard Watts (2003) view politeness phenomena from a primarily sociological perspective (for the discussion see Watts 2003: 56-81).

Despite this fundamental difference, it is interesting to note that both the pragmatic and the socio-linguistic theories consider politeness to be a form of cooperation: ${ }^{4}$

- Lakoff understands politeness as a linguistic means developed by societies to reduce social friction in personal interaction (1975: 64);

- for Leech, it consists in strategic conflict-avoidance with a view to establishing and maintaining interpersonal comity (1983);

- Brown and Levinson treat politeness as a set of linguistic means for softening face threatening acts (1987);

- Ardnt and Janney see it as "interpersonal supportiveness" (1985: 282);

- Hill et al. define politeness as a constraint on human interaction, the goal of which is "to consider other's feelings, establish levels of mutual comfort, and promote rapport" (1986: 349);

- not far from this is Watts's idea of politic behaviour defined as "cooperative social interaction and displaying mutual consideration for others" (Watts 2003: 14);

- even Fraser and Nolen, who view politeness in seemingly egocentric terms of "repay" and "reward," concede that it is a joint venture directed at social harmony and equilibrium (1981).

It seems that researchers of politeness accept the existence of a set of linguistic means which serve to facilitate friendly interaction and diffuse interpersonal conflicts. Some of them, most importantly Brown and Levinson (1987), take these means to be inherently polite; others, for example Watts (2003) and Eelen (2001), emphasise the role of interactional context in eliciting politeness judgements (i.e. statements that something is polite, impolite, or neither). However, no significant politeness theory denies that certain linguistic usages are commonly linked to the expression of politeness. Refraining from a critical evaluation of politeness research, this study will

4 The following presentation is based on Watts (2003: 53). 
focus on a few important classes of these usages, subsumed under the rubrics of formalisation, impersonalisation, deference, and optativeness.

\subsection{Formalisation and impersonalisation}

Formalisation is a notoriously elusive concept which has long bewildered stylisticians (see Turner 1973: 185-194). A valuable insight into its nature is provided by David Crystal's description of formality as the converse of conversational style. From this viewpoint, formality consists in:

- explicitness and context-independence; for example, the preferential use of nominals to pronouns, as in: "Give me a nice apple" in contrast to "Give me a nice one;"

- the use of complex clause patterns involving, for example, embeddings (such as relative clauses) and subordinations (such as hypotactic clauses);

- the use of "high" register, the use of explicit politeness markers (such as courtesy subjuncts: "thank you," "please," "excuse me"5) and the oratorical style of delivery (Crystal 1987: 52).

Impersonalisation seems a more easily identifiable notion. Brown and Levinson distinguish as many as nine strategies used by conversants to impersonalise their relation 1987: 190-209); the commonest among these include: ${ }^{6}$

- the use of passive and circumstantial voices (e.g. "It is regretted that..."),

- replacement of personal pronouns with indefinites (e.g. "One might think that..."),

- point-of-view distancing, such as the present-past tense switch (e.g. "I was wondering whether...") or the use of distal markers (e.g. "That pub is a den of iniquity"),

- invocation of general rules (e.g. "I'm sorry, but late-comers cannot be seated till the next interval"),

- nominalisation (e.g. "I am surprised at your failure" instead of "I am surprised that you failed").

5 For more on courtesy subjuncts see Quirk et al. (1985: 570-572).

6 Brown and Levinson's corpus is multilingual; the strategies given here are commonest in English. The strategies omitted from the survey include: the use of performatives, pluralisation of the "I" and "you" pronouns, the use of address terms of "you" avoidance, the use of reference terms of "I" avoidance. 
Brown and Levinson complete their account with the remark that impersonalisation is an important characteristic of linguistic formality (1987: 208). This seems to agree with the commonsensical intuition that the above strategies are in fact markers of the formal style: most of the above examples are structurally more complex than their less formal paraphrases (e.g. passive or tense-backshifted clauses when compared to active or present tense clauses), and practically all of them can be employed in the oratorical style of delivery. Furthermore, formalisation and impersonalisation, as defined above, often appear in concurrence; for example in "That pub is a den of iniquity" the use of the distal marker "that" (impersonalisation) is accompanied by the high register phrase "a den of iniquity" (formalisation) and in "I'm sorry, but latecomers cannot be seated till the next interval", the invocation of the general rule (impersonalisation) is again accompanied by the high register item the verb "seat" (in contrast to the more colloquial "sit"). ${ }^{7}$ Naturally, it is possible to insert low or neutral register terms into the slots occupied by the high register items (e.g. "That pub is a real dive" or "The late-comers will have not a place to sit") $)^{8}$; however, more often than not, impersonalisation strategies create the expectation that high register items should be used. In many cases, flouting this expectation renders stylistically deviant sentences, such as "It is regretted that you flunked your exam," where the low register item "flunk" conflicts with the formal layout of the sentence marked by the passivisation and the use of "that" clause.

Both formalisation and impersonalisation can be jointly explained in terms of discourse distancing. Accordingly, the elimination of personal pronouns, the use of passive and indefinites as well as the invocation of general rules should be seen as attempts to objectify ${ }^{9}$ the context of an utterance. The nature of this process is well captured by the stage metaphor concept proposed by Langacker (1987: 122-123). For instance, when the speaker formulates a request by invoking a general rule, as in "Friends always share," rather than through a direct appeal to the hearer, as in "Give me a bite of your apple," the speaker thus shifts herself and the hearer from the onstage position to the audience position. With no explicit assertion of the hearer as the agent performing the requested action and the speaker

7 However, taking into consideration purely syntactic criteria, it should be observed that there is no lexical choice between "seat" and "sit" in the context of the passive voice.

8 Broadly speaking, "The late-comers will not have a place to sit" can be considered as equivalent to utterances containing the verb "seat" such as "We will not be able to seat latecomers".

9 The concept of pragmatic objectification used here should be distinguished from objectification in the context of metaphorical processes; for the latter see Szwedek (2004). 
as the beneficiary of the requested action, they both assume the position of onlookers, not direct participants, of the scene described by the utterance.

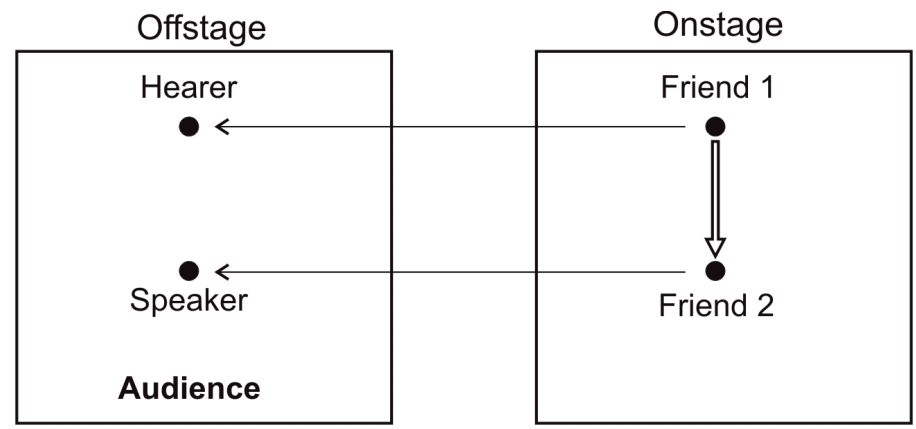

Figure 1. The "stage metaphor" interpretation of the utterance "Friends always share;" the arrow indicates the activity of sharing

In this way, the immediacy of the relation between the speaker (= the requester) and the hearer (= the requestee) is removed and retrievable only through inference:

Minor premise: $\quad$ You are my friend.

Major premise: Friends always share.

Conclusion: $\quad$ You have to share your apple with me.

It should be observed that the speaker announces only the major premise; the minor premise, which describes the relation between interactants, is retrievable from the context but not explicitly stated. The social effect of the speaker's strategy is that it brackets the relation between the interactants and thus serves to increase personal distance between them.

A comparable goal is accomplished by what Brown and Levinson identify as point-of-view distancing (1987: 204-206); here, it is the context of an utterance, not the relation between interactants, that is either temporally or spatially dislocated ("I was wondering whether you could give me a bite of your apple;" "That pub is a den of iniquity"):

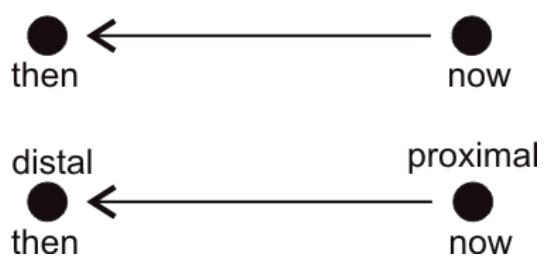

Figure 2. The temporal and spatial types of point of view distancing 
Furthermore, nominalisation, grammatical completeness, and the use of high register may be explained in terms of yet another type of distancing. For example, the use of nominals in preference to pronouns - as in "Give me a nice apple" instead of "Give me a nice one" - presupposes the existence of cognitive distance between the speaker and the hearer. The speaker implies a cognitive asymmetry between herself and the hearer in that the hearer is assumed to lack contextual knowledge necessary for the identification of "one" as "apple:"

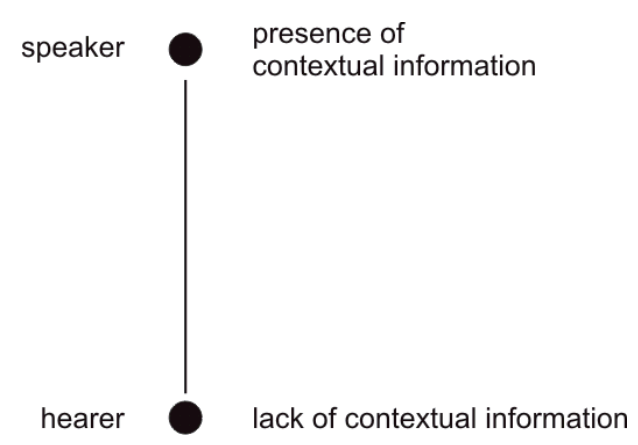

Figure 3. The process of cognitive distancing based on nominalisation, grammatical completeness, and the use of high register

Similarly, grammatical completeness and high register may indicate the speaker's assumption about the hearer's inability to understand elliptical, fragmented utterances or inability to understand more familial - jargon or slang - expressions:

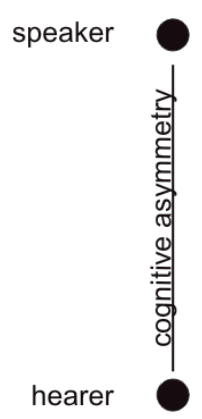

Figure 4. The principle of cognitive asymmetry

The above presentation indicates that impersonalisation and formality are accountable in terms of distancing, which in turn promotes the view that maintaining and/or increasing interpersonal distance is essentially polite. 
On a more general level, these observations may be used in support of the deictic view of discourse organisation proposed by Miller and JohnsonLaird (1976: 375ff) or by some cognitive linguists (e.g. see Langacker 2001). Accordingly, politeness strategies can be seen as consisting in the strategic manipulation of temporal, spatial, or cognitive distances between interactants. In all cases analysed here, utterances which accentuate personal distance appear more polite than their proximal equivalents. It is then possible to conclude that politeness is associated with distal discourse deixis:

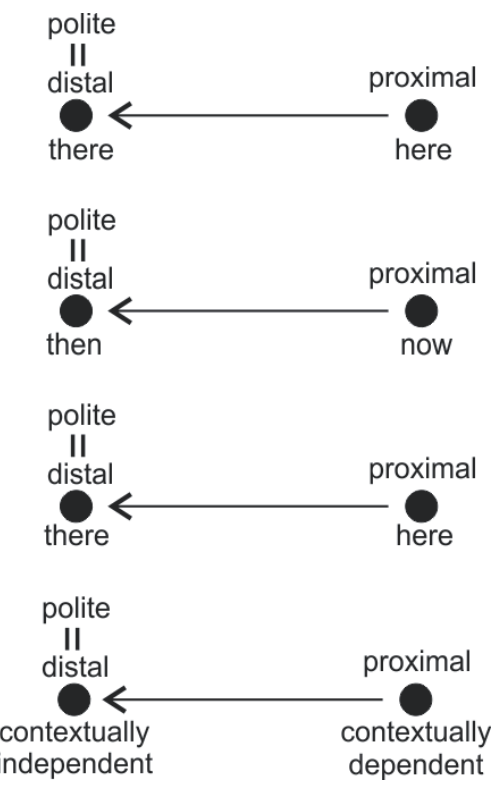

Figure 5. Politeness and discourse deixis at the spatial, temporal, and cognitive levels

\subsection{Deference}

The notion of deference was originally used in sociological and sociolinguistic studies. For example, Erving Goffman employed it in explicating his ritualistic model of interaction. Deference is identified there with "symbolic means by which appreciation is regularly conveyed" to a fellow interactant (Goffman 1967: 56). The common linguistic means of displaying appreciation include greetings, compliments, and apologies - in Goffman's terms, they perform the role of ritual gifts proffered during social intercourse (1967: 57).

In the field of linguistics, deference has come to be associated with the study of honorifics. Pioneering research in this area was conducted 
by Roger Brown - in collaboration with Albert Gilman on the pronouns of solidarity in tu-vos languages ([1960] 1972) and in collaboration with Michael Ford in research devoted to address terms in American English ([1961] 1972). Brown and his co-writers conclude that the principal function of honorificativeness is to code group identification and, specifically, the principal function of honorifics is to expresses the out-group relation between interactants and non-honorific ones, the in-group relation (Brown 1972: 122-123). From this perspective, deference is understood as the out-group marking carried out by means of honorifics. Later cross-linguistic studies strongly suggest that Brown's finding may well be universal, although the entrenchment of honorific/non-honorific distinctions is variable in different languages and primarily depends on the social organisation of a given speech community (Kuno 1973 and Comrie 1976).

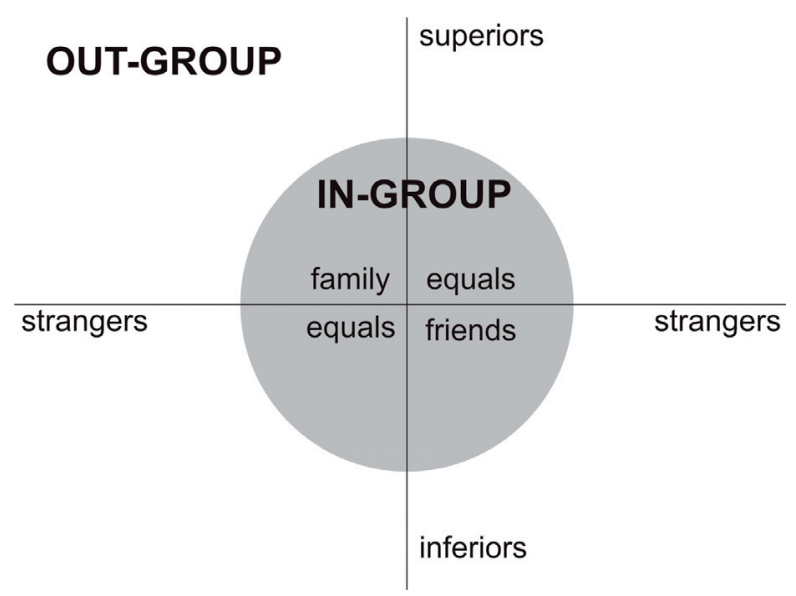

Figure 6. The processes of in- and out-group marking at the horizontal scale of familiarity and the vertical scale of power

In English, out-group marking is primarily effected by means of address terms. In particular, out-group markers belong to two classes of honorific terms of address: honorific pronominals and honorific nominals. As regards the former, Brown and Gilman ([1960] 1972) refer to two major patterns of pronominal addressing encapsulated in the symbolic distinction between TU (from the Latin $t u$ ) as a familiar pronoun and VOS (from the Latin vos) as a polite pronoun. This differentiation transfers onto nominal forms of address, which are studied by Brown and Ford (1972). Taken from everyday American English, the two equally strong options of addressing consist respectively in the use of first name only, including abbreviated 
or diminutised forms (labelled FN) and the use of titular address with the last name (labelled TLN). The dyadic in-group or out-group marking tends to proceed according to three major patterns, effected by pronominal and/ or nominal address terms. These are two reciprocal patterns, indicating either mutual familiar relations between interactants or mutual distance, and a non-reciprocal relation. Nonetheless, pronominal address terms constitute a limited set of address markers. In most European languages there is a choice between two or three pronominal forms of address, whereas in principle there is no inherent limit to nominal address options, with FN and TLN constituting the opposed ends of the friend-stranger spectrum.

Titles such as "sir", "madam" or "miss" (T) used to constitute an important group of address forms. Nowadays, their occurrence as separate address terms is extremely rare, and it characterises the maximum of deference related to contexts in which the last name is either not known or its use is forbidden. For example, "sir" frequently occurs in military usage or other hierarchically structured communities' jargons by low-ranking individuals to their remote superiors.

The use of last name alone (LN) pertains to situations of intimacy "greater than TLN but less than FN" (Brown \& Ford 1972: 134). Again, it is common in hierarchically organised groups, such as the army, where it is non-reciprocally used by officers to enlisted men and is reciprocally used among low-ranked soldiers. As Brown and Ford note, the use of last name alone, outside playful contexts, "always... go[es] with the mutual antagonism that blocks progression to intimacy" (Brown \& Ford 1972: 134). The use of "multiple names" $(\mathrm{MN})$ is "the case in which two or more versions of the proper name are used in free variation with one another" signalling relation of intimacy equal to or greater than FN. Such a degree of familiarity often leads to intentional phonetic distorting of proper names, resulting in a proliferation of address options (Brown \& Ford 1972: 135). The tendency to multiply forms of address can easily be explained by the semantic-psychological principle that "the degree of lexical differentiation of a referent field increases with the importance of that field to the community" (Brown \& Ford 1972: 136).

The non-reciprocal pattern of nominal addressing may be a result of direct or indirect subordination of an interactant in any speech situation. Direct subordination is related to difference in social status typical of the relations master-servant, employer-employee, and the like; indirect subordination describes a perceivable difference in status, not linked to a hierarchical arrangement within an institution, characterising, for example, the relation between a senator and a firemen (Brown \& Ford 1972: 132). Uneven social relationships can be enduring, when related to educational background, age, 
or birth (e.g. aristocratic descent), or temporary, involving, for example, occupational identities (such as waiter, shoe shiner or shop assistant) or lack of familiarity. In the last case, the pattern of address may evolve, proceeding from non-reciprocal to reciprocal addressing (see Brown and Ford's model Brown \& Ford 1972: 140).

The basic function of out-group marking seems to consist in highlighting status and/or personal distance. The non-reciprocal usages of $\mathrm{V}$ pronominal forms and T and TLN constitute the basic means of indicating out-group marking. The politeness effect related to out-group marking is an essentially distancing operation, which takes place on the vertical axis of power and/ or the horizontal axis of familiarity (see Fig. 6). Generally speaking, both pronominal and nominal out-group markers are able to code personal distance on either of the scales. ${ }^{10}$ The uses of address terms to create distancing effects on the vertical axis can be designated as elitist out-group marking and on the horizontal axis, as egalitarian out-group marking. For example, T and TLN have non-reciprocal uses as elitist out-group markers (i.e. when referring to superiors), and reciprocal ones as egalitarian out-group markers (i.e. when referring to strangers). However, both of these types pertain to the process of out-group marking. Since out-group marking serves the basic function of expressing distance between interactants, its different forms should be jointly classified as personal distancing, no matter on which of the axes distancing process takes place.

\subsection{Optatitveness}

The concept of optatitveness was introduced by Robin Lakoff (1973) with reference to politeness effects generated by conventionally indirect utterances. It is useful to view optative phenomena in terms of the hearer's freedom. For example, in the utterance "Could you do that?," where an optative strategy of politeness is used and which can be contrasted with the non-polite "Do that!," politeness effects are generated by giving the hearer the option of interpreting the utterance as a request to perform the designated action or as a question about her ability to perform the designated action; the non-polite equivalent does not present the hearer with such an option. Thus, in "Could you..." the speaker's strategy is to show respect to the hearer's right to the freedom of action. The politeness effect is strengthened by the use of the preterite "Could," which dislocates the request into what can be

10 In hierarchically organised communities the scope of out-markers is limited coding status differences on the vertical axis of power. 
designated as the region of discursive irrealis in that it removes the request from the discursive present into the discursive past (it is not the actual past because the request still holds).

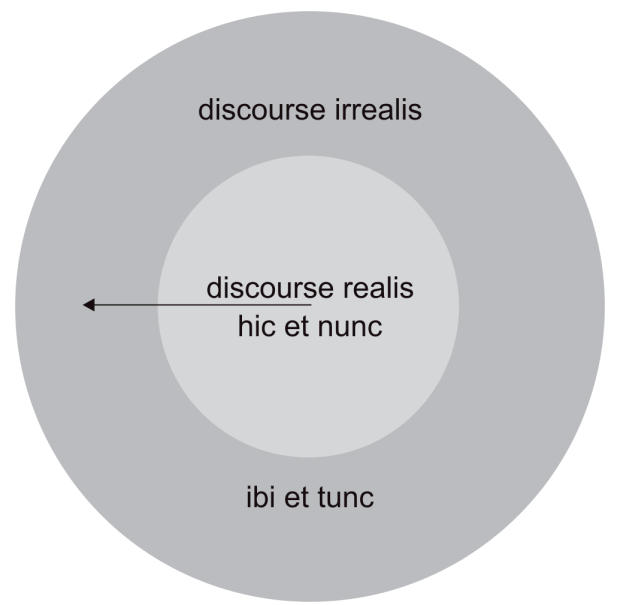

Figure 7. A shift from the realis domain of discourse to the irrealis domain

Generally speaking, freedom, or rather discursive freedom, arises from the fact that once a directive has been dislocated in the discursive space, the hearer may select between its interpretations: the covert and intended realis interpretation, which commits the hearer to performing the action indicated by the speaker, and the overtly signalled irrealis interpretation, according to which the course of action indicated by the speaker is hypothetical (when coded by a question or a conditional) and/or belongs to the past (when coded by the preterite).

The effect of this manipulation consists in increasing the distance between the speaker and the hearer. For example, in saying, "Couldn't you possibly wait for me?," the speaker transposes her request into the irrealis region of discourse, but, it should be stressed, such an action does not result in altering the interactional configuration: the speaker is still the requester and the hearer, the requestee. What it does accomplish is decreasing the immediacy of the speaker-hearer relation - the hearer is given the discursive freedom (but not the interactional freedom) to interpret the utterance as a request or not as a request (the freedom afforded by the use of the question format), to interpret it as representing what the speaker wants now or what he wanted in the past (the freedom afforded by the use of the past form), and to interpret it as representing what the speaker wants or what the speaker does not want (the freedom afforded by the use of negation). 
Although the interactional identities of the speaker and the hearer are intact, the dislocation of the request into the irrealis region creates a gap between the interactional role of the speaker as the actual requester and her discursive role as the hypothetical requester; similarly, a gap is created between the interactional role of the hearer as the actual requestee and her discursive role as the hypothetical requestee. The politeness effect of such discursive manipulation seems to consist in highlighting the social distance between the speaker and the hearer.

\subsection{Proxemics of politeness}

The description of the essential processes of linguistic politeness formalisation, impersonalisation, deference, and optativeness - suggests the view of politeness as an essentially territorial mechanism. Accordingly, politeness should be understood as a set of interactional strategies which allow interactants to decrease distance between them. There appear three types of such strategies. The first of them consists in dislocating discourse into the region of irrealis, that is, moving it from the discursive hic et nunc (= the proximal pole of discourse deixis) to the discursive ibi et tunc (= the distal pole of discourse deixis). This is primarily done through the use of optative strategies, but a similar effect is accomplished by some impersonalisation strategies, such as point of view distancing, the use of distal markers and passive voice, or invoking general rules. This type of discursive manipulation can be referred to as discourse dislocation (i).

The other major type of distancing is related to the cognitive situation of the speaker and hearer. Strategies associated with the formal style (most importantly, the use of grammatical completeness, nominalisation, and high register) presuppose the existence of a cognitive distance between the speaker and hearer - the speaker assumes that the hearer lacks contextual or sociolinguistic information to properly interpret elliptical utterances, pronominal referents, or slang and non-standard expressions, and therefore must be presented with grammatically complete and sociolinguistically standardised messages. It has been explained that the politeness effect of cognitive distancing (ii), as it will be designated, consists in the affirmation of cognitive asymmetry, which is strategically employed with a view to emphasising personal distance between interactants and not to announcing an essential difference in their knowledge.

Finally, there is a class of out-group marking strategies which constitutes probably the most apparent type of discursive distancing. Out-group marking takes place on the two axes - the horizontal axis of interpersonal distance and 
the vertical axis of status distance; the use of full names as well as honorifics referring to sex and marital status instantiate the distal pole of the horizontal axis, while elitist in-group markers (mainly familial terms of address, such as "father", "mother" and the like) and status honorifics (e.g. professional titles) instantiate the distal pole of the vertical axis. Discourse manipulation based on out-group making will be referred to as personal distancing (iii). The three types of discursive distancing are graphically illustrated below:

a)

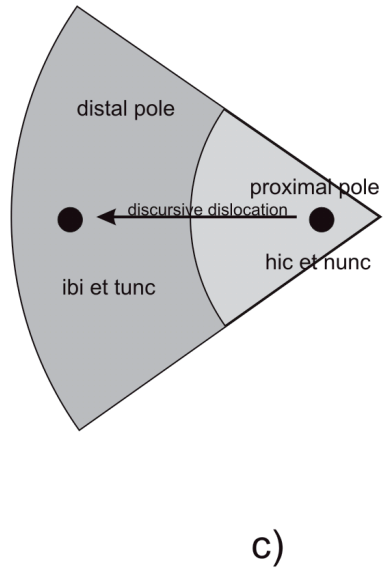

b)

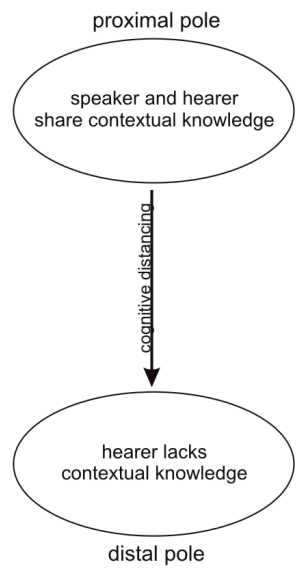

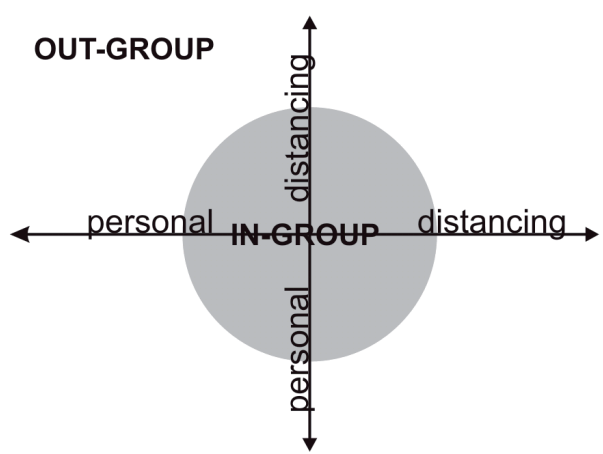

Figure 8. Types of discursive distancing: discourse dislocation (a), cognitive distancing (b), and personal distancing (c)

To capture their territorial nature, these processes will be referred to as sociofugal - the term derived from Edward T. Hall's proxemics describing spatial arrangements, both static (e.g. architectural and interior designs) and dynamic (i.e. spatial behaviours during conversations), which are conducive to increasing personal distance between interactants (Hall 1969: 108-110, 122-123). As will be shown in the section below, there is a vital link between 
politeness and proxemics, and the decision to use Hall's term is meant to indicate this relationship.

\subsection{Sociofugal politeness in conversational behaviour}

For this to happen, it is important to determine the role that sociofugal politeness plays in linguistic interaction. In doing so, a study on the distribution of politeness strategies in short conversational exchanges will be consulted. The study was based on a corpus of 54 adjacency pairs, that is, pairs of functionally related turns, such as question-answer, greeting-greeting, or offer-acceptance (Żywiczyński 2010: 201-279, 355-368; see also Sacks 1992, Sacks \& Schegloff 1973). Out of these, 37 interactions exhibited the dispreferred scenario (see Wootton 1981, Pomerantz 1984), in which the second turn contained a declination of the goal stated in the opening turn (dispreferred moves included e.g. a rejection of an offer, invitation, or request, a negation of an assessment, a lack of an answer). The remaining samples were preferentially organised, with the second turn affirming the goal stated in the original turn (e.g. accepting an offer or an invitation, granting a request, and the like). When investigated for the presence of sociofugal strategies, the dispreffered and preferred sequences showed a systematic difference. Among the former, 27 exhibited the characteristics of sociofugal politeness in dispreferred turns; in the seven interactions where the use of sociofugal politeness was not recorded, the dispreferred turns were expressed by means of either attributable silence or backchannel signals functionally equivalent to those which are attributable. As regards the dispreferred turns in which sociofugal politeness was used, as many as twenty showed the accumulation of politeness strategies, comprising both discourse dislocation strategies and cognitive distancing strategies; from the remaining seven, three contained only discourse dislocation strategies and four only cognitive distancing strategies. The following offer-refusal exchange is a typical example of the dispreffered-turn format:

[27] Turn1 A: Uh if you'd care to come and visit a little while this morning I'll give you a cup of coffee

Turn 2 B: hehh ((delay)) Well ((ANNOUNCER)) that's awfully sweet of you

((APPRECIATION)), I don't think I can make it this morning

((DECLINATION)) I'm running an ad in the paper and I have to stay near the phone. ((REASON))

(Levinson 1983: 333-334) 
Turn 2 is characterised by a complex distancing operation, involving both discourse dislocation and cognitive distancing processes. As regards the former, the announcer "well" and the qualifier "I don't think" together with the modal "can" dislocate the discourse in the region of epistemic irrealis - the politeness effect is achieved by expressing the refusal of the invitation by means of the hedge on the speaker's ability to fulfil the action mentioned in the prior turn (i.e. the hedge on the speaker's ability to come and have a cup of coffee with the inviter). Next, the dispreferred turn has the grammatically complete form - it is composed of three unfragmented, non-elliptical clauses and, given the standards of face-to-face interactions, is delivered in a relatively high register (note for example the use of the qualifying adverb in the phrase "awfully sweet") - these elements indicate that a cognitive distancing strategy is used.

As regards the preferred sequences, out of the total of 27 as few as five exhibited elements of sociofugal politeness, and among these, none showed the accumulation of sociofugal strategies: in one exchange a discourse dislocation strategy was used, and in the remaining four the interactants solely resorted to cognitive distancing. The results for the preferred and dispreferred turns are compared in the table below, with percentage values for the occurrence of sociofugal politeness:

Table 1. Distribution of sociofugal politeness strategies in preferred and dispreferred turns

\begin{tabular}{|c|c|c|c|c|}
\hline \multicolumn{5}{|c|}{ DISPREFERRED TURNS } \\
\hline \multirow{2}{*}{$\begin{array}{c}\text { The total } \\
\text { number } \\
\text { of interactions } \\
\text { with } \\
\text { dispreferred } \\
\text { turns } \\
\end{array}$} & \multicolumn{3}{|c|}{ Dispreferreds with elements of sociofugal politeness } & \multirow{2}{*}{$\begin{array}{c}\text { Dispreferreds } \\
\text { where } \\
\text { sociofugal } \\
\text { politeness was } \\
\text { not used }\end{array}$} \\
\hline & $\begin{array}{c}\text { both discourse } \\
\text { manipulation and } \\
\text { cognitive distancing } \\
\text { strategies }\end{array}$ & $\begin{array}{c}\text { only } \\
\text { discourse } \\
\text { manipulation }\end{array}$ & $\begin{array}{l}\text { only cognitive } \\
\text { distancing }\end{array}$ & \\
\hline \multirow[t]{2}{*}{34} & 20 & 3 & 4 & 7 \\
\hline & \multicolumn{3}{|c|}{27} & \\
\hline $\begin{array}{l}\text { Percentage } \\
\text { value }\end{array}$ & \multicolumn{3}{|c|}{$73 \%$} & \\
\hline \multicolumn{5}{|c|}{ PREFERRED TURNS } \\
\hline \multirow{2}{*}{$\begin{array}{c}\text { The total } \\
\text { number } \\
\text { of interactions } \\
\text { with preferred } \\
\text { turns }\end{array}$} & \multicolumn{3}{|c|}{ preferreds with elements of sociofugal politeness } & \multirow{2}{*}{$\begin{array}{c}\text { preferreds } \\
\text { where } \\
\text { sociofugal } \\
\text { politeness was } \\
\text { not used }\end{array}$} \\
\hline & $\begin{array}{c}\text { both discourse } \\
\text { manipulation and } \\
\text { cognitive distancing } \\
\text { strategies }\end{array}$ & $\begin{array}{c}\text { only } \\
\text { discourse } \\
\text { manipulation }\end{array}$ & $\begin{array}{l}\text { only cognitive } \\
\text { distancing }\end{array}$ & \\
\hline \multirow[t]{2}{*}{27} & 0 & 1 & 4 & 22 \\
\hline & \multicolumn{3}{|c|}{5} & \\
\hline $\begin{array}{l}\text { Percentage } \\
\text { value }\end{array}$ & \multicolumn{3}{|c|}{$19 \%$} & \\
\hline
\end{tabular}


The above analysis testifies to the existence of a non-trivial difference between preferred and dispreferred sequences in the distribution of sociofugal strategies. The contrast is so marked that even a study based on such a small corpus seems sufficient to draw the conclusion about the unique role that sociofugal politeness plays in the structure of dispreferred turns. It can be argued that the explanation of this difference is linked to the discursive role of dispreferred turns. In the organisation of discourse, they mark points which have the potential for conflict and confrontation - a dispreferred conflicts with an original goal of an interaction (to have one's offers accepted, requests granted, and so forth per analogiam) and in this way introduces an element of social friction into a discourse. In this context, sociofugal politeness seems to fulfil a compensatory function, allowing the speaker to distance herself from a dispreferred action that she is taking. Given the escalatory potential of dispreferred actions and the distancing character of politeness strategies used in them, it can be argued that sociofugal politeness performs an appeasing role in the way that, according to the ethological model of spacing, flight behaviours are used to appease aggression. To elaborate on this observation, the model in question must be briefly described.

\section{The ethology of spatial behaviours}

From the ethological perspective, aggression and flight belong to one behavioural complex, designated as the agonal system:

Fighting System

- Aggressive behaviour

Threat

Fighting

- Defensive behaviour

Threat

Fighting

Flight System

- Submissive behaviour

Flight behaviour

(Eibl-Eibesfeldt 1989: 363)

The relation between the fighting system (specifically aggressive behaviour) and the flight system was formulated by Charles Darwin in terms of the antithesis principle, whereby an aggressive individual tries to appear larger and encroaches on the territory of a submissive individual, who - by contrast - attempts to look smaller and shows readiness to give its 
territory to the opponent (Darwin 1872/1896; see also Bailey 1987: 411ff). Hence in the classic ethological model of spacing, which is derived from Hediger (1950, 1961) and Lorenz ([1949] 1994), territorial trespass is linked to aggressive behaviours while distance-lengthening, to their appeasement. Furthermore, appeasement displays, including distance-lengthening, are commonly used in the absence of overt aggressive behaviours to reduce the likelihood of a fight in the first place (Bailey 1987: 411). Reasoning along the ethological lines, they should be understood as behavioural strategies whose function is to prevent an encounter from taking an agonal course. Following Eibl-Eibesfeldt (1989: 493), a behavioural strategy is understood here as an action (such as a retreat or other submissive signal) taken with a view to achieving a specific goal (i.e. preventing aggression in the case at hand).

The expression of territoriality in humans is complex. Apart from its basic forms, such as site-dependent aggression and spatial aggression, human territoriality is expressed proxemically, that is, at the level of distancing behaviours which take place during interpersonal communication. According to Hall, the founder of proxemics, although their specific expression varies across cultures (1969: 113-130), the fundamental types of communicative distances and proxemic operations are universal and, possibly, have an instinctual basis (1969: 131-148) - or, as Bailey puts it, "the underlying biogrammar or infraculture of space is basically the same across cultures even though great surface variability may be present" (1987: 408). Indeed, Hall and others offer evidence showing that flight and critical reactions ${ }^{11}$ operate similarly in different cultures. For example, when engaged in a quarrel, people tend to increase the distance between themselves (deserting the scene of a quarrel is a typical reaction) (see e.g. DePaulo 1991). This is reported to happen unless the critical point is reached when the opponents come into close physical contact (Hall 1969: 114). In institutionalized settings, where the freedom of movement is confined, gaze or angularisation ${ }^{12}$ take over

11 These behaviours are related to Hediger's concepts of flight and critical distance (1955). Flight distance is the term Hediger uses to describe animal spacing behaviour in most cases, an animal flees when a potential attacker has encroached on its territory. Flight distance is correlated with critical distance, that is, a narrow belt which separates the flight zone from the attack zone.

12 Angularisation describes a degree alignment between interactants, measured in coronal plane (which divides the body into front and back), which is more than 0 degrees ( 0 degrees directly facing or squaring up) to 180 degrees (turning one's back). 
the function of the feet; for example, a boss tends to shun the gaze of an employee whom she wants to dismiss. ${ }^{13}$

It should be noted that flight reactions, or sociofugal operations as Hall designates them, perform the role of appeasement displays - they typically occur in agonal sequences with the specific task of overcoming aggression in the fellow interactant. Just as other appeasement displays (see above), proxemic distancing can also be used strategically to block aggression from arising in escalatory situations. Eibl-Eibesfeldt quotes a study of child behaviour in Yanomamo Indians as well as in German and Japanese kindergartens. In all three contexts, children were observed to increase interpersonal distance, angularise, and lower gaze in the presence of playmates who - they feared - could attack them (1989: 499).

In the previous section, the term "sociofugal" was used with reference to the set of politeness phenomena because they seem to fulfil the same function as strategic distancing which takes place at the proxemic level of interaction - both of these operations serve aggression appeasement and conflict avoidance. ${ }^{14}$ According to such a proxemic interpretation, at critical moments of interaction, conversants perform strategic distance manipulations, not in the physical space, but in the space of discourse, by employing discourse dislocation strategies (i) (e.g. on-stage-to-off-stage shifts or the use of conventional indirectness), cognitive distancing strategies (ii) (e.g. the use of high register and grammatically complete utterances), and personal distancing strategies (iii) (effected, primarily, by out-group marking).

The above proposal rests on the important human-ethological assumption that "There is... a universal rule system, a universal grammar of social behavior according to which verbal and nonverbal are similarly structured" (Eibl-Eibesfeldt 1989: 499). In the case at hand, verbal and nonverbal actions have the same - sociofugal - character and perform the same interactional function of blocking aggression. This idea is accompanied by an evolutionary claim that the developing linguistic faculty gradually appropriated the pre-existent nonverbal sociofugal operations, thus giving rise to linguistic politeness (at least of the type described in this article).

The motivation for the transfer from the proxemic to linguistic medium is likely to be the following. As micro-studies suggest, interpersonal

13 For details on the relation between proxemic behaviours and gaze, see Argyle and Dean (1972).

14 This is very much in line with the views on the function of politeness expressed by Robin Lakoff and, even more so, by Brown and Levinson. 
communication requires that interactants should be positioned face-to-face in close proximity. A typical conversational exchange involves the vis-àvis presentation ${ }^{15}$ (Scheflen 1972: 239ff) and personal distance, the term originally used by Hediger to indicate space separating members of noncontact species (1955) and adopted by Hall with reference to the distance in which people hold most of informal meetings (1969:119-120). The exact delimitation of personal distance differs from culture to culture, but it possesses a set of universal characteristics; for example, it is long enough to prevent visual distortion, which occurs in intimate distance; foveal vision covers face, torso, and arms; head size is perceived as normal and details of facial expression are clearly visible; speech is characterised by conversational style, moderate level of voice, and neutral tempo of delivery (Hall 1969: 119ff). Taking it all together, such a micro-ecological make-up provides an interpersonal encounter with what Goffman calls focus - a sense of togetherness which enables people to openly cooperate by taking turns at talking (1963: 24).

\section{The evolutionary perspective}

Reverting to the origin of linguistic politeness, the argument to be presented here rests on the assumption that conversation, in particular carried out in relaxed social settings, represents the evolutionarily primary type of language use (Dunbar 1997: 231-232; see also Dunbar 1993, Dunbar 1996, Gärdenfors 2003, and Dessalles 2007). Given this, the micro-ecological constraints spelt out in the previous section must have held for protolinguistic communication and exerted a formative influence on the shape of developing language. Using MacNeilage's scenario, proto-conversations can be described as exchanges of semantic vocalisations between interactants who are engaged in face-toface encounters (2008: 95-96). Taking into account the micro-ecological constraints on conversational behaviour, at potentially escalatory moments of such exchanges, participants, who intended to prevent an interaction from taking an agonal course, would find it difficult to employ appeasement displays, such as flight actions, without jeopardising effective conveyance of vocal messages. Putting it in Goffman's terms, a sudden increase in the

15 "Presentation" describes a general postural orientation adopted by one person in a given interaction and is distinguished from smaller postural units - "point," which corresponds to a postural micro-shift, and "position," which is a sequence of points (Scheflen 1972: 230-237). 
physical distance between conversation participants, even if performed for appeasing purposes, could easily break the focus of the interaction and lead to its termination, as demonstrated by research on interactional pathology (such as studies into the effects of compulsive flight reactions on the course of conversation; see Goffman 1967: 113-136; Hall 1969: 11-12; Birdwhistell 1970, 1972; Scheflen 1972). Arguably then, the logistics of face-to-face vocal communication created pressure to transfer the performance of sociofugal operations into the vocal medium, which eventually led to the development of politeness.

Presumably, this process fell into two basic phases. The first of them, which can be referred to as the iconic stage, consisted in lengthening a proto-conversational turn, for example, by means of delays, repetitions, prefaces, or apologies. In this way, increase in the time of turn delivery could substitute increase in the physical distance between interactants. At this juncture, it should be noted that that turn-lengthening seems to be a universal characteristic of politeness. Such a view is shared by Leech (1983: 108ff), on the one hand, and Brown and Levinson (1987: 142-147), on the other. More importantly, it is supported by Jan-Ola Östman's cross-cultural experiments on an artificial language, which demonstrate that longer messages, either due to the length of a whole sentence or the length of individual words, are consistently interpreted as more formal, and hence more polite, than their shorter equivalents with the same semantic content (Östman 1989). Since most of iconic operations do not involve the use of rich lexis and complex syntax, this phase in the evolution of politeness could have started at the very early stage of proto-linguistic vocal communication - if the hand-to-mouth scenario is accepted, it may have been occurring even during the transition from the gestural to vocal modality.

By contrast, mechanisms of sociofugal politeness described in this paper require the existence of a well developed language system; specifically, high degrees of lexical differentiation and grammaticalisation seem to constitute its key pre-requisites. On the lexical part, a language system of that sort must have possessed synonyms that allowed speakers to change register (Hurford 2003: 53); vocabulary for relational concepts - most importantly - spatial relation terms, which gave discourse a deictic structure, as well as markers of illocutionary force and modality (Jackendoff 2002: 252-259); and finally addressative terms, the earliest of which probably originated as names for atomic familial relations (Ehlich 2005). As regards syntax, many strategies of discourse dislocation and cognitive distancing involve the use of advanced phrase structure, auxiliary verbs, preterite forms, and subordination. It can be therefore concluded that a recursive, flexible, and grammaticalised 
language system promotes the development of these aspects of sociofugal politeness. This is not to say that for linguistic politeness to emerge, all such innovations should already have appeared. Rather, as proto-language was evolving into modern language (see e.g. Hurford 2003 and Jackendoff 2002: 131-164 for possible scenarios), its increasing expressive power stimulated an incremental growth of politeness phenomena.

Simon Kirby (2002) argues that the transition between proto- and modern language occurred through cultural transmission - given the socionormative character of politeness phenomena, it is even more likely that their emergence was culturally shaped, whereby a speech community's model of politeness reflected both the available linguistic resources and its social organisation. For example, there is some empirical ground to believe that less grammaticalised languages rely more on personal distancing strategies, effected mainly by address terms, than more grammaticalised ones, which favour discourse dislocation and cognitive distancing. It should, however, be stressed that the progressive appearance of sociofugal politeness should be understood as a general trend in the evolution of language, which - in the manner described above - led to transferring spatial appeasement signals into the linguistic medium.

How it was possible for this transfer to occur can be explained along Donaldian lines. Merlin Donald believes that the evolution of language was involved in a more general adaptation, geared towards expanding hominid mimetic skills $(1991,1999)$. In his view, mimesis is construed as a supramodal cognitive capacity, which allowed hominids to rehearse, refine, and re-enact action patterns. It can be speculated that abstract analogue representations of events which arose in this way helped them view vocal interactions as deictically organised. When this happened, the emergent "space of discourse" could be manipulated for social purposes, such as displaying solidarity, aggression, or submission. Possibly, the iconic phase in the evolution of politeness was then inaugurated; later, the growth of linguistic resources encouraged the development of complex sociofugal phenomena, identified here as strategies for discourse dislocation, cognitive distancing, and personal distancing. It should be remembered that Donald considers mimesis to represent an early stage in the development of the human minds and a pre-adaptation for the emergence of language. ${ }^{16}$ This is consistent with the argument presented above: mimetic skills pre-existed

16 He postulates that the mimetic capability arose in Homo erectus; the two later stages in the evolution of the human mind are related to the emergence of mythic culture and technologically-based culture (1991). 
protolanguage, and when it appeared (in the vocal form), they allowed interactants to conceptualise vocal exchanges in spatial terms.

\section{Outstanding questions}

It should be admitted that the view on the development of linguistic politeness laid out in this article is couched in very hypothetical terms. To go beyond the postulative character of this proposal, it is necessary to further investigate politeness phenomena themselves as well as their relation to proxemic operations. First of all, the universality of sociofugal politeness should be demonstrated. Although there is some empirical evidence suggesting that the mechanisms of discourse dislocation, cognitive distancing, and personal distancing have a wide distribution across languages (see Żywiczyński 2010: 391-438), this thesis stands in want of a thorough verification, in particular with reference to an influence of socio-linguistic factors on the variability in the occurrence of particular strategies. Next, an exhaustive functional description of sociofugal politeness should be given. Here, the argument about its appeasing role was uniquely based on the study of dispreferred turns. Other studies indicate that in different contexts politeness serves the same purpose. For example, the accumulation of sociofugal strategies in an utterance seems to be proportional to the degree of imposition contained in it; hence, it can be concluded that an increased risk of an interaction taking an agonal course increases the intensity of appeasement displays.

Another range of problems which should be further researched concerns the relation between spatial behaviours and aggression. The basic premise accepted here that in interpersonal communication lengthening distance reduces aggression was based on circumstantial evidence derived from ethology and proxemics. Since the relation between space and aggression is a complex one ${ }^{17}$ the premise in question must come under strict empirical scrutiny. Besides, paleo-anthropological studies should be consulted with a view to determining the extent to which aggression exerted a formative influence on hominid and early human groups. Finally, the argument about the proxemic origin of politeness would be greatly enhanced by micro-analyses

17 For example, a number of independent studies indicates that mere enlargement of living space is not unidirectionally related to a decrease of aggression in a population; compare Henk Nijman and Gust Rector's analysis of crowding and aggression in inpatient psychiatric wards (1999) with Frans de Waal's work on the relation between space and aggression in captive primates (1989). 
of the ratio between physical and discourse distancing in conversational interaction. But for all this to happen, the present work must end, thereby allowing others to speak.

\section{References}

Aitchison, J. (2000). The seeds of Speech. Language Origin and Evolution. Cambridge: Cambridge University Press.

Argyle, M. \& Dean, J. (1972). Eye Contact, Distance and Affiliation. In: J. Laver \& S. Hutcheson (Eds.), Communication in Face to Face Interaction (pp. 301316). Harmondsworth: Penguin Books.

Armstrong, D. F., Stokoe, W. C. \& Wilcox, S. E. (1994). Signs of the origin of Syntax. Current Anthropology 35(4), 349-368.

Arndt, H. \& Janney, R. (1985). Politeness Revisited: Cross-Modal Supportive Strategies. IRAL, International Review of Applied Linguistics in Language Teaching, 23(4), 281-300.

Bailey, K. (1987). Human Paleopsychology. Applications to Aggression and Pathological Processes. London: Routledge.

Birdwhistell, R. (1970). Kinesics and Context: Essays on Body Motion Communication. Philadelphia: University of Pennsylvania Press.

Brown, P. \& Levinson, S. (1987). Politeness: Some Universals in Language Usage. Cambridge: Cambridge University Press.

Brown, R. \& Gilman, A. (1972). The Pronouns of Power and Solidarity. In: J. Laver \& S. Hutcheson (Eds.), Communication in Face to Face Interaction (pp. 103-127). Harmondsworth: Penguin Books.

Brown, R. \& Ford, M. (1972). Address in American English. In: J. Laver \& S. Hutcheson (Eds.), Communication in Face to Face Interaction (pp. 128-145). Harmondsworth: Penguin Books.

Bühler. K. (1934). Sprachtheorie. Die Darstellungsfunktion der Sprache. Jena: Gustav Fischer.

Comrie, B. (1976). Linguistic Politeness Axes: Speaker-Addressee, SpeakerReference, Speaker-Bystander. Pragmatics Microfiche, 1.7, A3-B1.

Corballis, M. (2002). Did Language Evolve from Manual Gestures? In: A. Wray (Ed.), The Transition to Language: studies in the evolution of Language (pp. 161-179). Oxford: Oxford University Press.

Crystal, D. (1987). The Cambridge Encyclopedia of Language. Cambridge: Cambridge University Press.

Deacon, T. (1997). The Symbolic Species. The Co-evolution of Language and the Human Brain. London: Penguin Press.

DePaulo, B. (1991). Nonverbal Behavior and Self-Presentation: A Developmental Perspective. In: R. S. Feldman \& B. Rimé (Eds.), Fundamentals of Nonverbal Behavior (pp. 351-397). Cambridge: Cambridge University Press. 
Dessalles, J.-L. (2007). Why We Talk: The Evolutionary Origins of Language. Oxford: Oxford University Press.

Donald, M. (1991). Origins of the Modern Mind. Cambridge, Mass.: Harvard University Press.

Donald, M. (1999). Preconditions for the Evolution of Protolanguages. In: M. Corballis \& S. Lea (Eds.), The Descent of Mind: Psychological Perspectives on Hominid Evolution (pp. 138-154). Oxford: Oxford University Press.

Dunbar, R. (1993). Coevolution of Neocortical Size, Group Size and Language in Humans. Behavioural and Brain Sciences, 16(4), 681-735.

Dunbar, R. (1996). Grooming, Gossip and the Evolution of Language. London: Faber and Faber.

Dunbar, R., Marriott, A. \& Duncan, N. (1997). Human Conversational Behavior. Human Nature, 8(3), 231-246.

Eelen, G. (2001). A Critique of Politeness Theories. Manchester: St. Jerome.

Ehlich, K. (2005). On the Historicity of Politeness. In: R. Watts, S. Ide \& K. Ehlich (Eds.), Politeness in Language: Studies in its History, Theory and Practice (pp. 71-107). Berlin: Mouton de Gruyter.

Eibl-Eibesfeldt, I. 1989. Human Ethology. New York: Aldine de Gruyter.

Fraser, B. \& Nolen, W. (1981). The Association of Deference with Linguistic Form. International Journal of the Sociology of Language, 27, 93-109.

Gärdenfors, P. (2003). How Homo Became Sapiens: On the Evolution of Thinking. Oxford: Oxford University Press.

Goffman, E. (1963). Behavior in Public Places: Notes on the Social Organization of Gatherings. New York: Free Press.

Goffman, E. (1967). Interaction Ritual: Essays on Face-to-Face Behavior. New York: Doubleday.

Hall, E. (1969). The Hidden Dimension. New York: Doubleday.

Hediger, H. (1950). Wild Animals in Captivity. London: Butterworth.

Hediger, H. (1955). Studies of the Psychology and Behavior of Captive Animals in Zoos and Circuses. London: Butterworth.

Hewes, G. W. (1996). A history of the study of language origins and the gestural primacy hypothesis. In: A. Lock \& C. Peters (Eds.), Handbook of human symbolic evolution (571-595). Oxford: Oxford University Press.

Hill, B., Ide, S., Ikuta, S., Kawasaki, A., \& Ogino, T. (1986). Universals of Linguistic Politeness: Quantitative Evidence from Japanese and American English. Journal of Pragmatics, 10(3), 347-371.

Hurford, J. (2003). The Language Mosaic and its Evolution. In: M. Christiansen \& S. Kirby (Eds.), Language Evolution (38-57). Oxford: Oxford University Press.

Jackendoff, R. (2002). Foundations of Language: Brain, Meaning, Grammar, Evolution. Oxford: Oxford University Press.

Jakobson, R. [1960] (1999). Linguistics and Poetics. In: A. Jaworski \& N. Coupland (Eds.), The Discourse Reader, (48-54). London: Routledge. 
Kirby, S. (2002). Learning, Bottlenecks and the Evolution of Recursive Syntax. In: T. Briscoe (Ed.), Linguistic Evolution through Language Acquisition (173204). Cambridge: Cambridge University Press.

Krebs, J. R. \& Dawkins, R. (1984). Animal Signals: Mind-Reading and Manipulation. In: J. R. Krebs \& R. Dawkins (Eds.), Behavioural Ecology: An Evolutionary Approach (2nd edition) (380-402). Oxford: Oxford University Press.

Kuno, S. (1973). The Structure of the Japanese Language. Cambridge, Massachusetts: Harvard University Press.

Lakoff, R. (1973). The Logic of Politeness, or Minding Your P's and Q's. Papers from the $9^{\text {th }}$ Regional Meeting of the Chicago Linguistic Society, 292-305.

Lakoff, R. (1975). Language and Women's Place. New York: Harper.

Langacker, R. (1987). Foundations of Cognitive Grammar. Volume I. Theoretical Prerequisites. Stanford: Stanford University Press.

Langacker, R. (2001). Discourse in Cognitive Grammar. Cognitive Linguistics, 12(2), 143-188.

Leech, G. (1983). The Principles of Pragmatics. London: Longman.

Levinson, S. (1983). Pragmatics. Cambridge: Cambridge University Press.

MacNeilage, P. (2008). The Origin of Speech. Oxford: Oxford University Press.

Maynard Smith, J. (1982). Evolution and the Theory of Games. Cambridge: Cambridge University Press.

McNeill, D., Bertenthal, B., Cole, J., \& Gallagher, S. (2005). Gesture-first, but no gestures? Behavioral and Brain Sciences, 28, 138-139.

Miller, G. A. \& Johnson-Laird, P. (1976). Language and Perception. Cambridge, Massachusetts: Harvard University Press.

Nijman, H. \& Rector, G. (1999). Crowding and Aggression on Inpatient Psychiatric Wards. Psychiatr Serv, 50, 830-831.

Östman, Jan-Ola. (1989). Testing Iconicity: Sentence Structure and Politeness. Belgian Journal of Linguistics, 4, 145-163.

Pomerantz, A. (1984). Agreeing and Disagreeing with Assessments: Some Features of Preferred and Dispreferred Turn Shapes. In: J. M. Atkinson \& J. Heritage (Eds.), Structures of Social Action. Studies in Conversation Analysis (57-101). Cambridge: Cambridge University Press.

Sacks, H. (1992). Lectures on Conversations. Volumes I and II. Oxford: Blackwell. Sacks, H. \& Schegloff, E. (1973). Opening up Closings. Semiotica, 7(4), 289-327. Scheflen, A. (1972). The Significance of Posture in Communication Systems. In: J. Laver \& S. Hutcheson (Eds.), Communication in Face to Face Interaction (225-246). Harmondsworth: Penguin Books.

Scott-Phillips, T. (2008). On the Correct Application of Animal Signalling Theory to Human Communication. In: A. Smith, K. Smith, \& R. Ferrer-i-Cancho (Eds.), Proceedings of the 7th International Conference on the Evolution of Language, (275-282). London - Singapore: World Scientific.

Szwedek, A. (2004). Objectification in Metaphorical Processes - Some Philosophical Issues. Lingua Posnaniensis, 46, 121-129.

Turner, G. (1973). Stylistics. Harmondsworth: Penguin Books. 
Waal, F. de (1989). The Myth of a Simple Relation between Space and Aggression in Captive Primates. Zoo Biology, 8(s1), 141-148.

Watts, R. 2003. Politeness. Cambridge: Cambridge University Press.

Wootton, A. (1981). The Management of Grantings and Rejections by Parents in Request Sequences. Semiotica 37(1/2), 59-90.

Żywiczyński, P. (2010). The Axiology of Spoken Interaction. An Essay on the Organisation of Conversational Behaviour. Toruń: Wydawnictwo Naukowe Uniwersystetu Mikołaja Kopernika. 